\title{
Effect of dilute sulfuric acid pretreatment on the physicochemical properties and enzymatic hydrolysis of coffee cut-stems
}

\author{
Juan Camilo Solarte-Toro a, Yessica Chacón-Pérez a , Sara Piedrahita-Rodríguez a , \\ Jhonny Alejandro Poveda Giraldo ${ }^{a}$, José António Teixeira ${ }^{\mathrm{b}}$, Konstantinos Moustakas ${ }^{\mathrm{c}}$, \\ Carlos Ariel Cardona Alzate ${ }^{\text {a, * }}$ \\ a Instituto de Biotecnología y Agroindustria, Departamento de Ingeniería Química, Universidad Nacional de Colombia sede Manizales, Km 07 Vía al \\ Magdalena, Manizales, Colombia \\ b Centre of Biological Engineering, University of Minho, Campus Gualtar, Braga, Portugal \\ c School of Chemical Engineering, National Technical University of Athens, Zographou Campus, Athens, Greece
}

\section{A R T I C L E I N F O}

\section{Article history:}

Received 31 July 2019

Received in revised form

16 December 2019

Accepted 15 January 2020

Available online 17 January 2020

\section{Keywords:}

Coffee cut-stems

Crystallinity index

Dilute sulfuric acid pretreatment

$\beta$-glucosidase supplementation

Enzymatic hydrolysis

\begin{abstract}
A B S T R A C T
Coffee-cut stems are a potential fermentable sugars source, which can be upgraded in different valueadded products and energy vectors. Nevertheless, there are few reports focused on the acid pretreatment and saccharification processes. Thus, this paper evaluates the effect of the acid pretreatment and saccharification conditions of coffee cut-stems to find the highest sugar yield. Thereafter, the influence of the residence time in the acid pretreatment and the $\beta$-glucosidase supplementation in the saccharification process were analyzed. The combined severity factor and crystallinity index were used as metrics to evaluate both processes. In all assays, an increase in the crystallinity index was observed. Furthermore, a nonlinear trend of the combined severity factor respect to the residence time in the acid pretreatment was evidenced. The highest sugar yield was $66.75 \%$ with a combined severity factor of 1.84 . The better saccharification process was achieved at combined severity factor of 2.01 with a digestibility of $43 \%$. The addition of $\beta$-glucosidase in the enzymatic hydrolysis allows increasing the value to $69.07 \%$. Hence, low temperatures, acid concentrations, and the $\beta$-glucosidase supplementation allows obtaining a high sugar yield from coffee cut stems.
\end{abstract}

() 2020 Published by Elsevier Ltd.

\section{Introduction}

The use of lignocellulosic biomass as feedstock is an increasing tendency in developing and developed countries as an alternative to decrease the excessive use of non-renewable resources [1]. Lignocellulosic biomass has been studied to produce different value-added products and energy vectors [2]. Moreover, this type of biomass has several advantages in comparison with other biomass sources (e.g., abundance, non-food competition, and low cost) [3]. Therefore, the valorization of lignocellulosic residues represents an opportunity to increase the incomes of a crop. In this way, the lignocellulosic residues from the coffee crop and processing (i.e., coffee-cut stems, spent coffee grounds, pulp, husk, and coffee silverskin) have a high potential to be upgraded in different

\footnotetext{
* Corresponding author. Universidad Nacional de Colombia - Sede Manizales, 170003, Manizales, Caldas, Colombia.

E-mail address: ccardonaal@unal.edu.co (C.A.C. Alzate).
}

marketable products. Indeed, a special interest has been focused on the potential use of coffee-cut stems (CCS) as feedstock in different biorefinery systems in the Colombian context [4].

CCS are considered as a potential feedstock owing to the high content of natural biopolymers such as glucan, xylan, mannan, arabinan, and galactan, which can be converted into soluble $\mathrm{C}_{6}$ and $\mathrm{C}_{5}$ sugars [5]. Moreover, CCS are a potential feedstock due to the high production rate (i.e., $0.6 \mathrm{~kg}$ per $\mathrm{kg}$ of coffee cherry processed). In fact, the production rate of CCS was 60 ton/h in 2017 [6]. However, the research focused on assessing the feasibility of CCS as feedstock to be upgraded though biotechnological processes has been incipient. For instance, Quintero et al. [7], reported a technical and economic study of the use of CCS as feedstocks to produce bioethanol. These authors reported that the total production cost using CCS is higher than the bioethanol production costs using other lignocellulosic residues. This result is attributed to the raw materials costs assumed in the economic evaluation of the process. In addition, the high bioethanol production costs can be attributed 


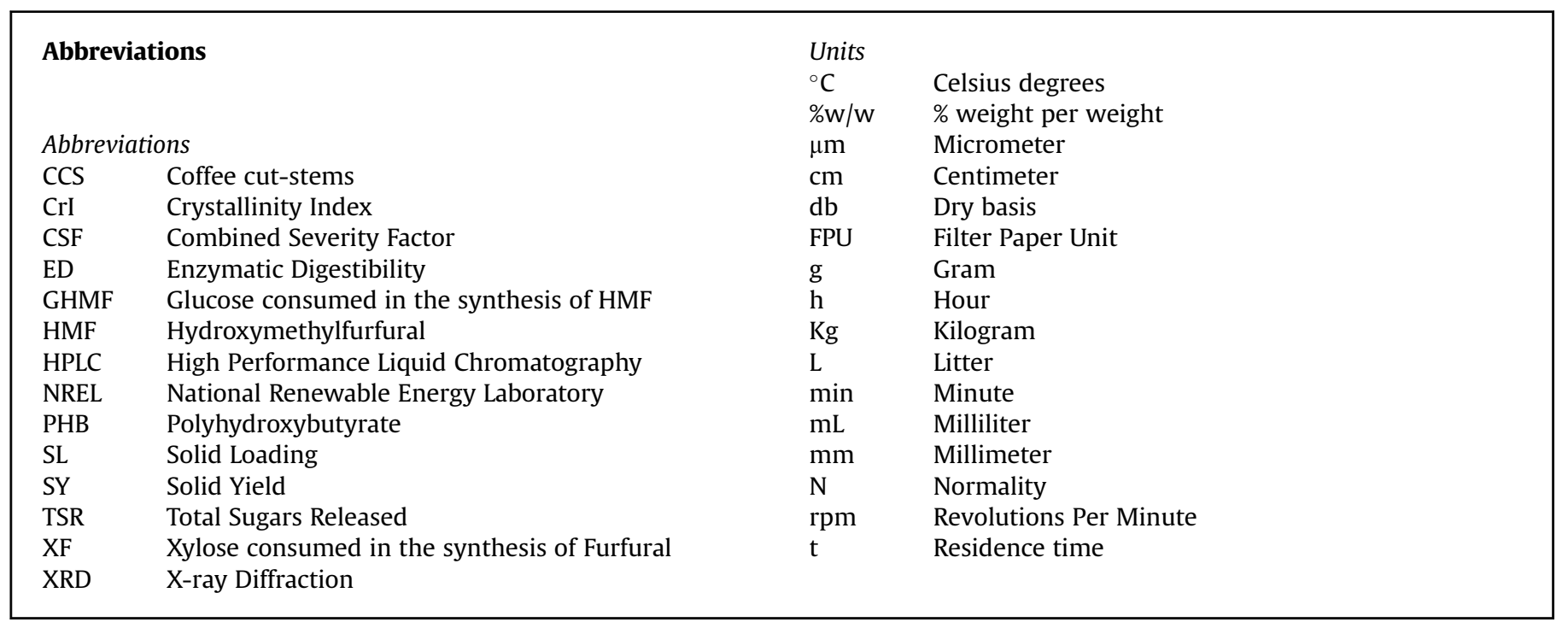

to the glucose yield calculated by the authors. In fact, the pretreatment and saccharification stages were calculated using a kinetic model developed for corn stover [8]. Therefore, the unselective use of a kinetic model to describe the behavior of different lignocellulosic materials in the pretreatment and saccharification stages is not the best approximation to evaluate the potential use of lignocellulosic biomass. Aristizábal et al. [14], corroborated this-statement through the experimental work to obtain xylose and glucose yields derived from the dilute acid pretreatment and enzymatic hydrolysis of sugarcane bagasse, rice husk, fique bagasse, and CCS. Nevertheless, the main concern identified in the saccharification process is the overall glucose yield obtained for CCS (i.e., 19\%), which is lower than the yields reported for sugarcane (i.e., 33\%) and fique bagasse (i.e., 40\%). These results and the glucose yields reported for other lignocellulosic residues are obtained due to the conditions handled during the pretreatment stage (i.e., $115{ }^{\circ} \mathrm{C}, 30 \mathrm{~min}$ and $5 \mathrm{~h}$ ). In fact, the dilute acid pretreatment stage must be performed considering the structure of the raw material, which allows improving the yields obtained in this process as well as the selection of the best operation conditions according to the type of biomass to be treated. In the CCS case, this raw material has a harder and more rigid structure than sugarcane and fique bagasse, which involves the use of more severe conditions. This statement is based on the plant taxonomy. Thus, the results obtained from a pretreatment stage depends strongly on the raw material and the dilute acid pretreatment conditions selected [9].

The operating conditions of the dilute acid pretreatment can change according to the raw material to be pretreated and the process requirements. The main variables to be considered in this pretreatment are the temperature, acid concentration, residence time and solids loading. In this sense, the temperature of the process can be in the range $100{ }^{\circ} \mathrm{C}-200{ }^{\circ} \mathrm{C}$. Moreover, the acid concentration can vary between $0.5 \%$ and $2.5 \%$ [18]. On the other hand, the solids loading and reaction time can be in the range 20-100 min, and 10\%-15\%, respectively [4]. Nevertheless, the temperature and residence time have a great influence on the generation of inhibitory compounds (e.g., aldehydes and phenolic acids), which should be considered before performing the pretreatment of a lignocellulosic feedstock [21]. Therefore, the study of this pretreatment can be handled from two perspectives. The first perspective is the optimization to reach a maximum yield of glucose. The second option is to describe the mechanism of the reactions through a kinetic model [22]. Even though, both perspectives should be researched for specific lignocellulosic materials due to the physicochemical properties vary significantly from one raw material to another. Then, the research at moderate conditions could help to identify the feasibility of new lignocellulosic materials in the biotechnological process.

CCS are a potential source of sugars after a pretreatment and saccharification stages. Nevertheless, the low enzymatic hydrolysis yields, as well as the low xylose yields reported in the literature, encourage to research the best way to pretreat this lignocellulosic residue. Therefore, the aim of this paper is to assay the effect of the dilute acid pretreatment operating conditions as well as the enzymatic hydrolysis of CCS to increase the total glucose yield. For this, a temperature of $120^{\circ} \mathrm{C}$ and five residence times were assessed in the dilute sulfuric acid pretreatment. Then, the effect of the $\beta$-glucosidase supplementation in the enzymatic hydrolysis was the main variable analyzed in saccharification process. In this way, the influence of the pretreatment on the physicochemical properties of CCS, the composition of hydrolysates and the conversion of glucose was analyzed through the combined severity factor (CSF) parameter. Finally, the mass balances of both processes (i.e., dilute acid pretreatment and enzymatic hydrolysis) are presented to elucidate the potential use of this raw material to be upgraded through biotechnological processes.

\section{Methodology}

\subsection{Raw material and chemicals}

Coffee crop is one of the most important and representative crops in Colombia. The CCS are the waste generated from the renewal of this cultivation [10]. The CCS samples were supplied by a local farmer in Manizales ( $\left.5^{\circ} 4^{\prime} 1^{\prime \prime} \mathrm{N} 75^{\circ} 31^{\prime} 1^{\prime \prime} \mathrm{W}\right)$. This city is situated in Caldas, which belong to the coffee growing areas located in Colombia. This raw material was washed using tap water until removing soil particles. CCS must be conditioned for both chemical composition analysis and dilute acid pretreatment. For this, the total amount of raw material was divided into two batches. CCS used in the acid pretreatment were dried at $45^{\circ} \mathrm{C}$, while CCS used in the chemical composition analysis were dried at $105^{\circ} \mathrm{C}$. Then, the dried solids were cut into small chips of $2.5 \mathrm{~cm}$ and milled in a two stage process using a laboratory scale knife mill (ThomasWiley mill). The milled CCS were sieved using ASTM standard 
sieves between 20 and 80 mesh. The retained fraction in the ASTM 40 sieve was stored at $20^{\circ} \mathrm{C}$ until use. Finally, the CCS were characterized according to the standard procedures developed by the National Renewable Energy Laboratory (NREL) [11].

The dilute sulfuric acid solution for the pretreatment step was prepared with a sulfuric acid at $95 \% \mathrm{w} / \mathrm{w}$. This acid solution was standardized using a standardized solution of sodium hydroxide $0.10 \mathrm{~N}$. The chemical reagents were purchased to Merck Millipore. The enzymes used in the saccharification stage were given by the Novozymes enterprise. On the other hand, the DNS method chemicals were purchased to Panreac. Finally, the chemicals used in section 2.4.1 were supplied by the Centre of Biological Engineering of the University of Minho (Braga, Portugal).

\subsection{Dilute sulfuric acid pretreatment}

\subsubsection{Selected conditions}

The process conditions of the dilute sulfuric acid pretreatment such as acid concentration, solids loading, temperature, and residence time were selected considering the principle of this pretreatment in terms of the combined severity factor (CSF). Previous results in the open literature for the CCS and similar lignocellulosic biomass results (i.e. hardwoods such as Aspen, Poplar, Eucalyptus, Maple, and Olive tree) also were considered to propose the pretreatment conditions [10,12-17]. Therefore, this process was performed in batch mode with a solid to liquid ratio of $1: 10$ (g CCS, db/ g) using a sulfuric acid solution of $2 \% \mathrm{w} / \mathrm{w}$ and a temperature of $120{ }^{\circ} \mathrm{C}$. Moreover, the $\mathrm{pH}$ value of the dilute sulfuric acid solution was 0.83 . Different residence times were applied in the pretreatment process. The CSF was used as parameter to decide the best set of variables. Yang et al. [13], reports the use longer residence times or higher temperatures when the concentration of the sulfuric acid solution is low. Therefore, the residence time in this study was varied from $20 \mathrm{~min}$ to $180 \mathrm{~min}$. Moreover, the residence time was changed to identify the effect on the saccharification process and the sugars released of the hemicellulose fraction. The CSF tested was calculated with equation (1) and presented in Table 1.

$C S F=\log \left(e^{\frac{T\left({ }^{\circ} \mathrm{C}\right)-100}{14.75}} \cdot t(\min )\right)-p H$

\subsubsection{Laboratory procedure}

A laboratory-scale batch reactor configuration conformed by glass flasks and an autoclave equipment were used to achieved the pretreatment operating conditions. Indeed, $8 \mathrm{~g}$ of milled and dried CCS were added into $500 \mathrm{ml}$ SCHOTT flasks. Then, the dilute acid solution was added until complete the solid to liquid ratio assuming a complete humectation of the raw material. Finally, the flasks were autoclaved at $120^{\circ} \mathrm{C}$ and $1 \mathrm{atmg}$ using a laboratory scale autoclave (MLS-3751, Sanyo). Each assay was performed in duplicate. Then, the liquid fraction was removed by filtration. This fraction was placed on falcon tubes to withdraw $2 \mathrm{ml}$ of sample. Then, this liquid sample was filtered using filters $(0.22 \mu \mathrm{m})$ and kept at $-20^{\circ} \mathrm{C}$ until sugar analysis. Instead, the solid fraction was washed because of inhibitors presence and the low $\mathrm{pH}$ achieved using distilled water until reach a $\mathrm{pH}$ of 4.8 . This $\mathrm{pH}$ value was set to perform the enzymatic hydrolysis. The required water to reach the desired $\mathrm{pH}$ value was $2.5 \mathrm{~L}$ at room temperature, which suggests a high water footprint of the dilute acid pretreatment [18]. Then, the solid fraction was divided into two fractions. The first solid fraction was oven-dried at $60^{\circ} \mathrm{C}$ to perform the calculation of the solid yield (SY) as well as to carry out the composition analysis of the pretreated
CCS. The SY was defined as the ratio between the dry matter of CCS recovered from the pretreatment to the dry matter of raw material employed in the process. The second solid fraction was used in a saccharification process.

\subsection{Saccharification process (enzymatic hydrolysis)}

The saccharification process was accomplished using Cellic $\mathrm{CTec} 2$ as enzyme cocktail provided by Novozymes (Denmark). The cellulose activity was measured following the NREL method [19]. In fact, the activity of the Cellic CTec2 was estimated in $123 \mathrm{FPU} / \mathrm{mL}$, which is in agreement to the enzyme activity reported by Zhao et al., [30]. Then, the enzymatic hydrolysis of the pretreated CCS was performed. This process was carried out inside an incubator with a fixed temperature, orbital agitation and time (i.e., $50{ }^{\circ} \mathrm{C}$, $150 \mathrm{rpm}$, and $72 \mathrm{~h}$ ). The total volume of the saccharification process was $50 \mathrm{~mL}$ using a $0.05 \mathrm{~N}$ sodium citrate buffer solution. The solid and enzyme loadings of the process were $5 \% \mathrm{w} / \mathrm{v}$ and $20 \mathrm{FPU} / \mathrm{g}$ dry substrate, respectively. The samples analysis was performed based on $1 \mathrm{~mL}$, and applying the DNS method [20]. A $\beta$-glucosidase supplementation was used to evaluate the effect of this enzyme in the total glucose yield of the process. For this, the $\beta$-glucosidase used had a protein concentration of $19.9 \mathrm{mg} / \mathrm{mL}$ and activity of 17.93 UIpNPG/mg protein in a ratio of 0.94 FPU/UIpNPG [21]. The $\beta$ glucosidase supplementation was done after to identify the best sugars yields using only Cellict CTec2. The results of this process were estimated using Equations (2) and (3).

\% Enzymatic Digestibility $(\mathrm{ED})=\frac{\mathrm{C}_{\mathrm{Glucose}}}{1.11 \text { Glucan }_{\text {Substrate }} \mathrm{SL}} \times 100$

$\%$ Total glucose yield $=\frac{\mathrm{C}_{\mathrm{Glucose}}}{1.11 \text { Glucan }_{\mathrm{CCS}} \mathrm{SL}} \times 100$

where $\mathrm{C}_{\text {Glucose }}$ is glucose concentration $(\mathrm{g} / \mathrm{L})$, Glucan Substrate $_{\text {is }}$ the amount of cellulose (i.e., glucan) in the treated CCS, Glucan ${ }_{\text {CCS }}$ is the cellulose content in the feedstock, SL refers to the solid loading for the enzymatic hydrolysis $(50 \mathrm{~g} / \mathrm{L})$, and 1.111 is the conversion factor of glucan to glucose based on a stoichiometric equation [22].

\subsection{Analytical methods}

\subsubsection{Chemical characterization of treated CCS and hydrolysates analysis}

The characterization pretreated CCS was completed using a twostep acid hydrolysis. The extractives content of the raw material was quantified applying a soxhlet extraction using water and ethanol as solvents [23]. The two-step acid hydrolysis was done assuming that the extractives content of CCS samples were solubilized during the acid pretreatment [5]. The liquors generated from the two acid hydrolysis as well as the hydrolysates of the pretreatment were analyzed in a HPLC system equipped with a column $87 \mathrm{H}(300 \times 7.8 \mathrm{~mm})$ Aminex (BioRad) with a RI and UV detectors. This was done to identify the $C_{6}$ sugars (i.e., glucose), $C_{5}$ sugars (i.e., xylose, arabinose), organic acids (i.e., acetic acid, formic acid) and inhibitors (i.e., HMF and furfural). The oven was adjusted

Table 1

CSF corresponding to the residence time considered in the dilute sulfuric acid pretreatment on CCS.

\begin{tabular}{llllll}
\hline CSF & 1.06 & 1.36 & 1.54 & 1.84 & 2.01 \\
\hline Residence time (min) & 20 & 40 & 60 & 120 & 180 \\
\hline
\end{tabular}


at $60{ }^{\circ} \mathrm{C}$ and the pump was fixed with a flow rate of $0.6 \mathrm{~mL} / \mathrm{min}$ using as mobile phase a $0.005 \mathrm{M} \mathrm{H}_{2} \mathrm{SO}_{4}$ solution. Data acquisition and processing were done through the aid of the Varian MS Workstation ${ }^{\circledR}$ software and the regression and graphical analyses with the commercial software (Microsoft Excel by Microsoft, USA). For each component quantified, the coefficient of determination $\left(\mathrm{R}^{2}\right)$ was 0.99 .

\subsubsection{XRD analysis}

X-ray diffraction (XRD) is a technique widely used to characterize the degree of crystallinity of lignocellulosic biomass identifying the amount of amorphous cellulose [32]. This analysis was done due to the acid pretreatment changes the cellulose structure through the disruption of the hydrogen bonding of cellulose fibrils [33]. Therefore, the analysis was done to evaluate the rupture of the lignocellulosic matrix of CCS after the dilute acid pretreatment comparing the initial and final degree of crystallinity. Then, the Xray characterization was carried out using a diffractometer RIGAKU MINIFLEX II with monochromatic $\mathrm{Cu}-\mathrm{K} \alpha$ radiation at $30 \mathrm{Kw}$ and $15 \mathrm{~mA}$ with a scanning rate of $5^{\circ} / \mathrm{min}(2 \theta)$ as well as a sampling width of $0.02^{\circ}$. Scans were obtained in a range from $3^{\circ}$ to $50^{\circ}(2 \theta)$ [24]. Therefore, the degree of crystallinity is expressed using the crystallinity index (CrI). This index is the relation between the two forms of the cellulose (i.e., crystalline and amorphous). Finally, the $\mathrm{CrI}$ was calculated applying the mathematical expression reported by Segal et al. [25], which is showed below:

$\% \mathrm{CrI}=\frac{\mathrm{I}_{002}-\mathrm{I}_{\mathrm{am}}}{\mathrm{I}_{002}} \times 100$

where $\mathrm{I}_{002}$ is the highest intensity of the diffraction at $2 \theta \approx 22.6^{\circ}$ and $\mathrm{I}_{\mathrm{am}}$ is the minimum intensity of the diffraction at $2 \theta \approx 19^{\circ}$. The data acquisition of these intensities was done with the software packages of Origin $8.6 \circledR$.

\subsection{Calculations}

The results of the pretreatment step were analyzed calculating different metrics. Indeed, the physicochemical characteristics of the liquid and solid fractions obtained in both acid pretreatment and saccharification were considered. Therefore, equation (5)-10 were used to identify the effect of the pretreatment processes on the CCS. In equations (7) and (8), the terms Xylose ${ }_{C C S}$ and Arabinose $e_{C C S}$ correspond to the sugar concentration in the pretreatment step. The values are $23.9 \mathrm{~g} / \mathrm{L}$ and $1.5 \mathrm{~g} / \mathrm{L}$, respectively. The Microsoft Excel software was used to perform these calculations and those corresponding to the statistical analysis.

Component recovery in the treated CCS:

$\%$ Recovery $=\frac{\text { Component in treated CCS x SY }}{\text { Component in raw material }} \times 100$

Component: Cellulose, Hemicellulose, and Lignin.

Component solubilization:

\% Solubilization $=100-$ \%ecovery

Xylose yield:

\%Xylose yield $=\frac{C_{\text {Xylose }}}{1.13 \text { Xylose }_{\mathrm{CCS}}} \times 100$

Total sugars released (TSR):

$$
\begin{aligned}
& \% T S R=\frac{C_{\text {Xylose }}+C_{\text {Arabinose }}}{1.13\left(\text { Xylose }_{\text {CCS }}+\text { Arabinose }_{\text {CCS }}\right)} \times 100 \\
& \mathrm{MW}_{\text {xylose }} / \mathrm{MW}_{\text {xylan }}=1.13 . \\
& \text { Glucose consumed in the synthesis of HMF: }
\end{aligned}
$$

$\mathrm{GHMF}=1.43 C_{H M F}$

$\mathrm{MW}_{\text {glucose }} / \mathrm{MW}_{\mathrm{HMF}}=1.42$.

Xylose consumed in the synthesis of Furfural:

$$
\begin{aligned}
& \mathrm{XF}=1.56 \mathrm{C}_{\text {Furfual }} \\
& \quad \mathrm{MW}{ }_{\text {xylose }} / \mathrm{MW}_{\text {furfural }}=1.56(\text { Eq. (10)). }
\end{aligned}
$$

\section{Results and discussion}

\subsection{Effect of the dilute sulfuric acid pretreatment on CCS}

The CCS composition in dry basis was (\%w/w, db): Extractives $(2.55 \pm 0.07)$, glucan $(41.53 \pm 1.82)$, xylan $(20.64 \pm 0.95)$, arabinan $(1.25 \pm 0.12)$, acetyl groups $(4.48 \pm 0.05)$, acid insoluble lignin $(29.05 \pm 0.22)$ and ash $(0.72 \pm 0.06)$. The dilute sulfuric acid pretreatment was analyzed considering the results obtained from the chemical characterization of the solid fraction and the soluble compounds quantification in the liquid fraction produced after the pretreatment. These fractions (i.e., solids and hydrolysates) were analyzed to complete the mass balances of the overall process.

\subsubsection{Sugars and inhibitory compounds in hydrolysates}

Dilute acid pretreatment has been used to release monomeric sugars able to be considered as a substrate in biotechnological processes to produce ethanol, xylitol, PHB and so forth [26]. Therefore, the identification and analysis of most of the components present in the hydrolysates (i.e., liquid fraction) in terms of sugar and inhibitory compounds concentration must be done. Thus, the concentration of glucose, xylose, and arabinose and sugars yield are showed in Table 2.

Low glucose concentrations were achieved in the hydrolysates (i.e., $0.52 \mathrm{~g} / \mathrm{L}-1.22 \mathrm{~g} / \mathrm{L}$ ), which indicates a low degradation of the CCS cellulose fraction. This is a typical behavior in this chemical pretreatment. In fact, the hemicellulose fraction is the target of this pretreatment, which explains the high xylose concentrations achieved in all assays (i.e., $8.35 \mathrm{~g} / \mathrm{L}-15.87 \mathrm{~g} / \mathrm{L}$ ) [27]. The hemicellulose structure composed by xylan, arabinan, mannan, and galactan is hydrolyzed due to the action of the acid catalyst and temperature, which break the chemical bonds of the hemicellulose components. The glucose concentration has an increasing trend respect to the CSF. Indeed, the glucose concentrations starts in $0.52 \pm 0.02 \mathrm{~g} / \mathrm{L}$ and finish in $1.22 \pm 0.02 \mathrm{~g} / \mathrm{L}$. Then, the severities used represent a low effect on the cellulose hydrolysis since the glucose yields have values lower of $3 \%$. In contrast, the arabinose concentration was reduced until a value of $0.63 \pm 0.07 \mathrm{~g} / \mathrm{L}$ with the increase of the severity. Thus, the arabinose yields were higher than $60 \%$ at low severity conditions and suddenly reduced until a value of $42.85 \%$ for the CSF of 2.01. Nevertheless, the arabinose released did not affect the TSR in comparison with the xylose. Sugar yields decrease at CSF of 2.01 (1.62\%, 36.02\% and $42.85 \%$ for glucose, xylose and arabinose, respectively), since the increase of residence time allows the degradation of sugars to other compounds, such as acetic acid, formic acid, HMF, furfural, among others. The maximum xylose concentration and yield were reached at CSF of 1.84. The values were $15.87 \pm 0.13 \mathrm{~g} / \mathrm{L}$ and $65.95 \%$, respectively. The concentration disagreed with the report of Aristizábal et al. [17], for the CCS. The xylose concentration of $19.58 \mathrm{~g} / \mathrm{L}$ was found at $115^{\circ} \mathrm{C}$ and $30 \mathrm{~min}$ of 
residence time (the CSF calculated corresponds to 1.08). Nevertheless, the xylose yield in this research represents $50 \%$ of the potential of the CCS. In this sense, the increase of the pretreatment severity allows obtaining high efficiencies related to the xylan degradation. Therefore, the best condition to obtain a high TRS was applying a CSF equals to 1.84 with a value of $66.75 \%$. This value is similar to the hemicellulose recovery reported by Martinez et al. [28], using olive tree biomass as raw material and acid pretreatment conditions of $160{ }^{\circ} \mathrm{C}, 25$ and $35 \% \mathrm{w} / \mathrm{w}$ (i.e., solids loading), 10 min of residence time, and acid concentrations of 4 and $8 \% \mathrm{w} / \mathrm{w}$.

The CCS xylose yields are lower than those obtained from the acid pretreatment of sugarcane bagasse and rice husk [17]. The obtained allows identifying the diverse effect of the pretreatment variables (i.e. residence time and acid concentration) with a fixed temperature of $120^{\circ} \mathrm{C}$ and solid: liquid ratio of $1: 10$ on the xylose yield. In fact, the obtained results are comparable with the xylose yields reported for hardwoods and softwoods [29]. In this sense, high xylose yields are obtained increasing both residence time and acid concentration in hardwood raw materials. This statement is corroborated by Parajo et al. [9], which needs a 3.5\% sulfuric acid solution and $10 \mathrm{~h}$ of residence time to perform the acid pretreatment of Eucalyptus. Thus, the pretreatment severity differs strongly when agricultural residues and woody biomass are used as raw materials. In fact, CCS gives a xylose yield of $34.68 \%$ applying a CSF of 1.07 , while xylose yields of $75.9 \%$ and 75.6 for rice straw and rice husk are reported, respectively [30]. Hence, the research of the best acid pretreatment conditions for woody biomass is should be done avoiding the use of the typical values reported in the literature. Moreover, high xylose yields could be achieved high temperatures and low residence times, solid: liquid ratio, and acid concentrations. However, the thermal degradation of the sugars is a risk factor. For instance, Canettieri et al. [31], reports an optimal point to pretreat Eucalyptus using a solid: liquid ratio of $1: 8.6$, sulfuric acid concentration of $0.65 \% \mathrm{w} / \mathrm{w}, 157^{\circ} \mathrm{C}$, and a residence time (20 min) to get a xylose yield of $79.6 \%$.

Table 3 presents the concentrations of other compounds (i.e., furaldehydes and aliphatic acids) found during the compositional analysis of the hydrolysates. They are derived from the hemicellulose deacetylation and the dehydration of sugars during the pretreatment. The presence of inhibitor compounds decrease the sugars consumption of different microorganisms, which reduces the fermentation productivity [32]. Among the aliphatic acids detected, significant quantities of acetic acid were liberated from the acetyl groups contained in the CCS until be fully hydrolyzed. A same behavior as for the sugars was presented for the acetic acid concentration increasing with the CSF until a concentration of $4.79 \pm 0.05 \mathrm{~g} / \mathrm{L}$ due to a large amount of acetyl groups in CCS. After the CSF of 1.84, the concentration was reduced until the half. The increase in the concentration of the inhibitory compounds (such as acetic acid, formic acid, HMF and furfural) is a product of the increase in residence time. Hemicellulose is mainly composed of the sugars xylose and arabinose (i.e., pentoses) and glucose, galactose and mannose (i.e., hexoses) in different proportions [33]. However, when degradation of these sugars occurs, the release of inhibitory compounds is triggered. In the case of xylose, degradation generates the release of furfural, and of arabinose and glucose, components such as formic acid and acetic acid are produced [34]. Therefore, an increase in the concentrations of furfural and acetic acid at CSF of 2.01 is evidenced. The maximum acetic acid concentration found is low in comparison with the concentrations reported in the literature (i.e., 7 or $10 \mathrm{~g} / \mathrm{L}$ ) [35]. Even so, the produced hydrolysates cannot be used directly in a fermentation process due to the possible presence of inhibitory compounds. In this way, the analysis of the suitability of the hydrolysates for fermentation must be carried out in a more specific and rigorous way. Indeed, different factors can affect a fermentation process to produce different pentose-based products through biotechnological processes (e.g., xylitol) [36]. Nevertheless, a detoxification stage should be performed to avoid the presence of inhibitory compounds in the fermentation media. Moreover, the presence of dissolved inorganic compounds and toxic components should be tested and avoided through a detoxification stage. Finally, Moreover, the pretreatment process does not have a high lignin solubilization due to the adverse effects of phenolic compound in fermentation processes [37].

The furaldehydes such as HMF and furfural were produced in most of the evaluated severity conditions due to the dehydration of glucose and xylose, while the formic acid is present by the hydration of HMF [38]. The concentration of these can be negligible compared with other reports since just values above $1 \mathrm{~g} / \mathrm{L}$ were achieved. This concentration affects the cell growth and productivity of microorganism [39]. Nevertheless, the concentrations of HMF and formic acid at the two final conditions (i.e., $\mathrm{CSF}=1.84$ and $\mathrm{CSF}=2.01$ ) were not detected by liquid chromatography. Then, a glucose concentration of $0.52-0.66 \mathrm{~g} / \mathrm{L}$ was degraded until HMF and a xylose concentration of $0.079-0.702 \mathrm{~g} / \mathrm{L}$ was converted in furfural during the pretreatment. The furfural concentrations quantified by HPLC analysis of the CCS hydrolysates are lower than the reported by different authors using similar pretreatment conditions in terms of residence time and temperature. For instance, $\mathrm{Yu}$ et al. [40], report a furfural concentration of $5 \mathrm{~g} / \mathrm{L}$ using sulfuric acid at $0.01 \% \mathrm{w} / \mathrm{w}$ after to pretreat cassava. Moreover, the furfural concentrations are lower than the data reported by Chiranjeevi et al. [41], (i.e., $2.40 \mathrm{~g} / \mathrm{L}$ ) using sulfuric acid at $0.75 \% \mathrm{w} / \mathrm{w}$ after pretreating rice straw. In this way, the low furfural concentrations obtained in the CCS hydrolysates are attributed to the low xylose yield and conversion obtained, which were explained due to the rigid structure of woody biomass. Thus, the low furfural concentrations are a consequence of both the acid pretreatment operating conditions and the type of biomass.

\subsubsection{Solid fraction analysis}

The dry matter content of the treated solids was $34 \pm 1.7 \%$, which corresponds to a SY between $0.68 \pm 0.01$ and $0.85 \pm 0.04$ for

Table 2

Sugar concentration and yields of the hydrolysate derived from the dilute sulfuric acid pretreatment of CCS.

\begin{tabular}{|c|c|c|c|c|c|c|c|c|c|c|c|c|c|c|c|}
\hline \multirow[t]{2}{*}{ Component } & \multicolumn{15}{|l|}{$\mathrm{CSF}$} \\
\hline & 1.06 & & & 1.36 & & & 1.54 & & & 1.84 & & & 2.01 & & \\
\hline Glucose (g/L) & 0.52 & \pm & 0.02 & 0.72 & \pm & 0.01 & 0.91 & \pm & 0.02 & 1.22 & \pm & 0.02 & 0.78 & \pm & 0.06 \\
\hline Xylose (g/L) & 8.35 & \pm & 0.11 & 11.36 & \pm & 0.01 & 12.91 & \pm & 0.18 & 15.87 & \pm & 0.13 & 8.67 & \pm & 0.87 \\
\hline Arabinose (g/L) & 1.00 & \pm & 0.04 & 0.94 & \pm & 0.01 & 0.96 & \pm & 0.01 & 1.07 & \pm & 0.02 & 0.63 & \pm & 0.07 \\
\hline Glucose yield (\%) & 1.08 & \pm & 0.08 & 1.49 & \pm & 0.06 & 1.88 & \pm & 0.09 & 2.52 & \pm & 0.08 & 1.62 & \pm & 0.10 \\
\hline Xylose yield & 34.68 & \pm & 0.06 & 47.19 & \pm & 0.02 & 53.64 & \pm & 0.08 & 65.95 & \pm & 0.12 & 36.02 & \pm & 1.01 \\
\hline Arabinose yield (\%) & 68.62 & \pm & 0.14 & 64.24 & \pm & 0.02 & 65.50 & \pm & 0.02 & 73.42 & \pm & 0.04 & 42.85 & \pm & 0.09 \\
\hline TSR (\%) & 36.83 & \pm & 0.19 & 48.44 & \pm & 0.09 & 54.63 & \pm & 0.17 & 66.75 & \pm & 0.11 & 36.62 & \pm & 1.21 \\
\hline
\end{tabular}


the CSF of 2.01 and 1.06, respectively. Then, the amount of solids recovered in the acid pretreatment process decreases with the severity [42]. This can expressed using the linear correlation \% $\mathrm{SY}=-18.10 \mathrm{CSF}+103.5\left(\mathrm{R}^{2}=0.98\right)$. In addition, the obtained SY results are in concordance with the wood yield reported by Gütsch et al. [43], applying a high residence time, low acid concentration, and temperature in Eucalyptus samples.

In Fig. 1, the results of the chemical composition of the treated CCS are presented. The cellulose fraction was analyzed in terms of glucan, while the hemicellulose fraction was analyzed in terms of xylan, arabinan, and acetyl groups. The same behavior was observed for each component of the treated solid respect to the CSF. Although no direct relation between the CSF or the SY and the glucan, lignin, arabinan, and acetyl groups content was found. In fact, a linear relation was presented for the CSF and the xylan content and solubilization with an $\mathrm{R}^{2}=0.92$. The equation for the xylan content was Xylan $\mathrm{CCS}=-2.02 \mathrm{CSF}+12.434$.

The glucan and lignin content were reduced with the increase of the severity factor obtaining high recoveries in the solid fraction (i.e., glucan: $63.0 \%-105 \%$ and lignin: $88.40 \%-90.69 \%$ ). Eventually, it was expected a reduction in all the cases for the glucan content since in the hydrolysates a consecutive increase in the glucose content was observed. However, the CSF of 1.36 allows having a high content of $45 \pm 2.6 \%$ with a recovery of $104.56 \%$. However, a decrease in the glucan content is perceived when the severity factor increases from 1.36. This is related to its solubilization in the medium, due to the high residence times that favor this process. In addition, a low lignin content of $26.2 \pm 0.4 \%$ was observed corresponding to a high percentage of lignin solubilization of $12.2 \%$. Therefore, this CSF can have a high effect on the disruption of the cross-linked matrix of the lignin and hemicellulose, thus the cellulose content embedded by the hemicellulose fraction could be able to be detected in the treated CCS. This behavior was also found by Gütsch et al. [43], for Eucalyptus treated at $120^{\circ} \mathrm{C}, 36 \mathrm{~min}$ and a sulfuric $0.1 \mathrm{M}$. The glucan content in the base at raw material was $40.33 \%$ compared with the $39.9 \%$ and the highest lignin solubilization of $24 \%$ for the same temperature. In this way, low temperature and residence time increase the glucan content respect to the raw material. Nevertheless, another technique to study the chemical changes of lignin and carbohydrates has to be applied to corroborate this behavior [44]. On the other hand, the reduction of the lignin content in all cases shows a lignin re-condensation during the dilute acid pretreatment was not present as in the case of the olive tree biomass considered by Martínez-Patiño et al., [28].

The hemicellulose fraction was the main lignocellulosic compound removed in all assays. The arabinan and acetyl groups were removed totality in all cases. The acetyl groups content in the other cases remains linked to the xylan backbone in a range of $1.7 \pm 0.1 \%$ for the CSF of 1.54 and almost the half of the present in the raw material at CSF of 1.06 (i.e. $2.4 \pm 0.5 \%$ ). Thus, high CSF values allow a complete hemicellulose deacetylation. The xylan content was $9.7 \pm 2.0 \%, 9.5 \pm 0.6 \%, 6.9 \pm 0.2 \%, 3.2 \pm 0.1 \%$ and $2.7 \pm 0.8 \%$ for each
CSF 1.06, 1.36, 1.54, 1.84 and 2.01, respectively. These results denote a great solubilization of the xylan, with the high value of $87.19 \%$ for the CSF of 2.01 and $100 \%$ for the arabinan and acetyl groups. Even though, the CSF of 2.01 represents the maximal point of hemicellulose fraction removal for the solid fraction, while in the liquid fraction the maximal point of TSR was the 1.86 due to the degradation of the sugars. Therefore, for the conditions of pretreatment selected, the increase of the residence time reduces the sugar release of the hemicellulose present in the CCS and an optimal point would be between the CSF of 1.54 and 2.01. Additionally, an increase of the temperature reduces the residence time and the acid concentration could represent a better scenario to have low glucan solubilization compared with the hemicellulose solubilization of 91.7\% reported for Poplar by Kumar et al., [45]. Nevertheless, the increase of temperature to $190{ }^{\circ} \mathrm{C}$ can represent an increase in the energy demand of this process step, which should be studied at the same time in terms of techno-economic assessments [46].

\subsection{Enzymatic digestibility (ED)}

The research seeks to improve the ED of CCS using the dilute sulfuric acid pretreatment to overcome the recalcitrance of this feedstock. This objective was formulated in the wake of the low glucose concentration obtained during the direct saccharification of CCS (i.e., $1 \mathrm{~g} / \mathrm{L}$ ). The results obtained for the saccharification process are presented in Fig. 2. An increase in the glucose concentration over the time was a general trend observed during the saccharification step of the treated solids. In fact, a notorious increase in the glucose release with the increase of the CSF was present. Therefore, the CSF of 2.01 achieves the maximal glucose release of $9.53 \pm 0.01 \mathrm{~g} / \mathrm{L}$ at $72 \mathrm{~h}$ compared with the $2.74 \mathrm{~g} / \mathrm{L}$ at CSF of 1.06 . Thus, the ED corresponds to $43.40 \%$ and $12.01 \%$, respectively. Then, the cellulose conversion of $19.67 \%$ achieved by Aristizábal et al. [17], with Celluclast $1.5 \mathrm{~L}$ and viscozyme was improved. In addition, the CSF of 2.01 has a great effect on the rate of glucose generated since at $7 \mathrm{~h}$ of saccharification more than $50 \%$ of the final glucose concentration was reached.

Nevertheless, a complete cellulose conversion was not achieved in the last CSF (i.e., 2.01). In this sense, a $\beta$-glucosidase supplementation was performed in order to show an improvement in the digestibility. The main action of this enzyme is to hydrolyze cellobiose to glucose. The glucose concentration was increased $74 \%$ respect to the assay without $\beta$-glucosidase supplementation at $48 \mathrm{~h}$. At this time, the concentration was similar to the reported value by Martínez et al. [47], in the olive tree pruning treated with phosphoric acid in a concentration of $1.5 \%$ at $170{ }^{\circ} \mathrm{C}$ during $10 \mathrm{~min}$ and a $30 \%$ total solids loading. Moreover, the total operation was extended to $117 \mathrm{~h}$ but only a difference of $2 \mathrm{~g} / \mathrm{L}$ was observed after 48 h. Therefore, the ED value was $64.13 \%$ representing an increase of $59 \%$ respect to the data without $\beta$-glucosidase supplementation.

In terms of the total glucose yield, a linear correlation was found with the severity. The highest value was $64.13 \%$ with the solids treated with a CSF of 2.01 and $\beta$-glucosidase supplementation. Even

Table 3

Concentration of Inhibitory compounds in the liquid fraction from the dilute sulfuric acid pretreatment of CCS.

\begin{tabular}{|c|c|c|c|c|c|c|c|c|c|c|c|c|c|c|c|}
\hline \multirow[t]{2}{*}{ Component } & \multicolumn{15}{|l|}{ CSF } \\
\hline & 1.06 & & & 1.36 & & & 1.54 & & & 1.84 & & & 2.01 & & \\
\hline Acetic acid & 3.18 & \pm & 0.01 & 3.55 & \pm & 0.11 & 3.78 & \pm & 0.03 & 4.79 & \pm & 0.05 & 5.20 & \pm & 0.18 \\
\hline Formic acid & 0.11 & \pm & 0.01 & 0.24 & \pm & 0.04 & 0.64 & \pm & 0.01 & N.D. & & & N.D. & & \\
\hline HMF & 0.36 & \pm & 0.04 & 0.38 & \pm & 0.10 & 0.47 & \pm & 0.11 & N.D. & & & N.D. & & \\
\hline Furfural & 0.05 & \pm & 0.01 & 0.09 & \pm & 0.02 & 0.14 & \pm & 0.01 & 0.58 & \pm & 0.07 & 0.61 & \pm & 0.05 \\
\hline
\end{tabular}

N.D.: Not detected. 
(a)
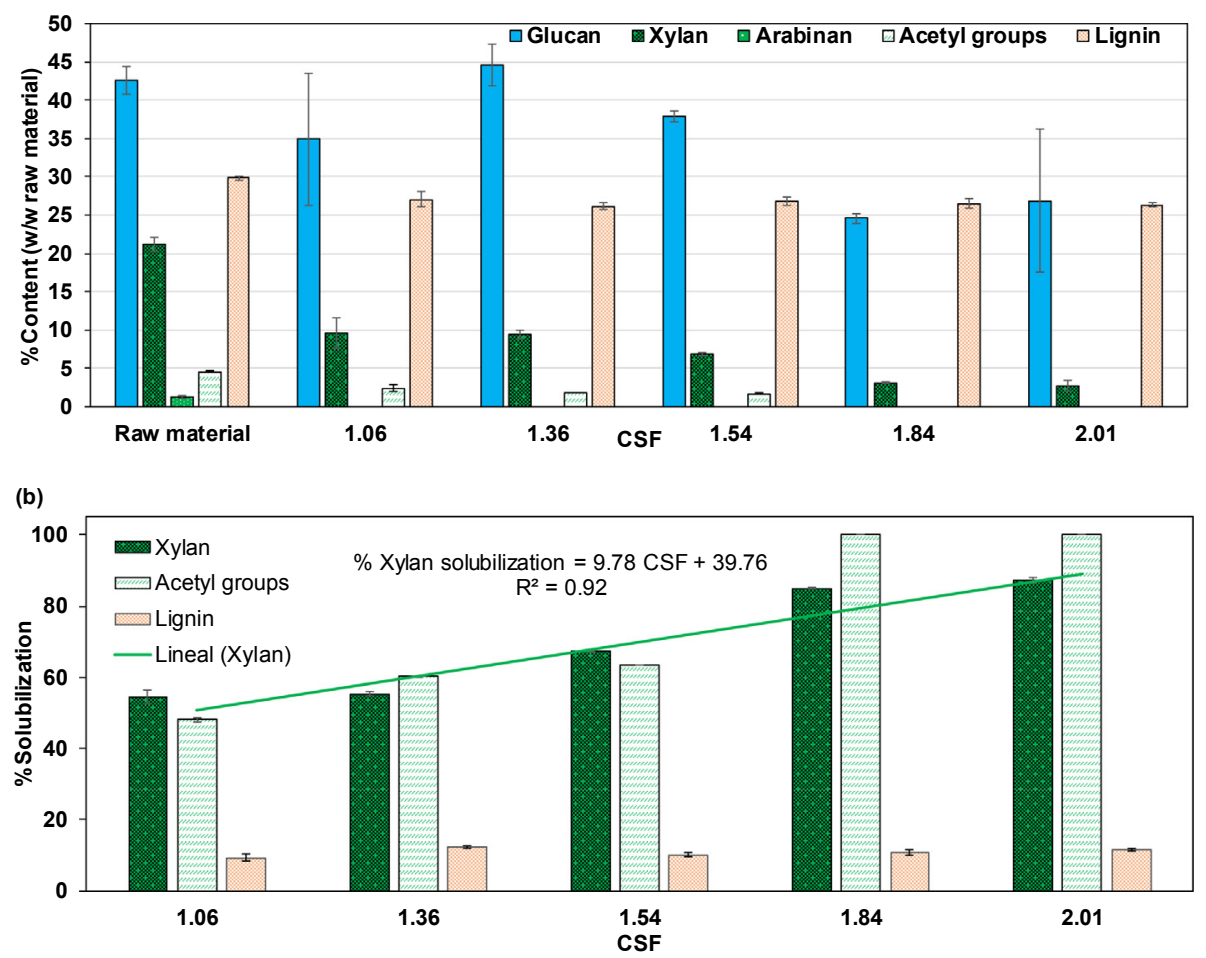

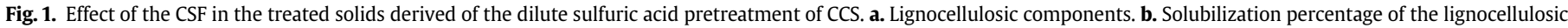
components.

though, this supplementation did not complete cellulose conversion of the raw material. In this case, the CSF of 2.01 allows the high total glucose yield, while the maximum value of the TSR is reached using a CSF of 1.84. Thus, two global mass balances can be performed depending on the purpose of the pretreatment process.

\subsection{Crystallinity index of the raw material and pretreated solids}

The disruption of the lignocellulose structure of CCS with and without the pretreatment was analyzed through the CrI. The results are presented in Fig. 3. These results were associated with the CSF applying a nonlinear correlation with an $\mathrm{R}^{2}=0.91$. For each assay, an increase in the crystallinity index respect to the CCS was identified. However, a value of $54 \%$ was detected when the $\mathrm{CSF}=1.06$ Therefore, the increase respect to the feedstock corresponds to $33 \%$, $29 \%$, and $23 \%$, respectively. Moreover, the increase of the CrI is possible owing to the removal of amorphous regions of cellulose, hemicellulose and lignin [48]. This result is similar to the data obtained for other hardwoods. In fact, Carrasco et al. [49], has applied conditions of $120{ }^{\circ} \mathrm{C}, 1\left(\% \mathrm{v} / \mathrm{v} \mathrm{H}_{2} \mathrm{SO}_{4}\right)$, a solid liquid ration of 1 : 10 , and different residence times on different hardwoods such as Poplar, Oak wood, and Eucalyptus. For each case, an increasing tendency of $15 \%, 17.54 \%$, and $28.14 \%$ was found. While, Kumar et al. [46], only achieve an increase in Poplar of $1.4 \%$ handling a temperature of $190{ }^{\circ} \mathrm{C}$, the residence time of $70 \mathrm{~s}$ and a low concentration of sulfuric acid of $0.6 \%$ and $4.5 \%$ [45]. The same happens with the investigation of Carvalho et al. [52], where an increase of $19.52 \%$ for Eucalyptus with a high temperature of $175{ }^{\circ} \mathrm{C}$, low residence time $15 \mathrm{~min}$ and concentration of sulfuric acid of $4.5 \%$ is observed. Then, these comparisons lead to identify two important factors of this index. The first factor is related to the increase of the $\mathrm{CrI}$ at low temperatures and acid concentrations using hardwoods as raw materials. The other statement is related to CCS could have a structure more amorphous than other hardwoods researched in this field since they have a high CrI. Furthermore, a linear correlation with an $\mathrm{R}^{2}=0.95$ between the \%CrI and the total glucose yield was found. The equation was \%Total glucose yield $=8.38 \% \mathrm{CrI}-$ 5.24 .

\subsection{Mass balance}

Two mass balances were constructed using the data obtained in the acid pretreatment and subsequent enzymatic hydrolysis of CCS. These are presented in Fig. 4. In both cases, $100 \mathrm{~g}$ of dry CCS and $1000 \mathrm{~g}$ of sulfuric acid solution were fed to the pretreatment. The CCS contain $42.62 \mathrm{~g}, 21.18 \mathrm{~g}, 1.29 \mathrm{~g}, 4.59 \mathrm{~g}$, and $29.81 \mathrm{~g}$ of glucan, xylan, arabinan, acetyl groups, and lignin, respectively. In the pretreatment stage, the residence time is the difference between the two scheme (i.e., $120 \mathrm{~min}$ and $180 \mathrm{~min}$ ). In each scheme, $70 \mathrm{~g}$ and $68 \mathrm{~g}$ of pretreated CCS are generated. Moreover, $771.3 \mathrm{~g}$ and $730 \mathrm{~g}$ of hydrolysates are produced. In the first scheme $0.82 \mathrm{~g}$ of arabinose and $12.24 \mathrm{~g}$ of xylose were released. In the second scheme the amounts of arabinose and xylose were reduced $50 \%$. The same happens with the glucan content corresponding to recoveries of $57.77 \%$ and $63 \%$ in schemes a and $\mathbf{b}$, respectively. This content is submitted to an enzymatic hydrolysis releasing 10.75 and $20.63 \mathrm{~g}$ of glucose. The possibilities to use these quantities in ethanol production are better for the scheme $\mathbf{b}$ since considering a synthesis of $90 \%$ of the theoretical yield of stoichiometric reaction around of $12.02 \mathrm{ml}$ per $100 \mathrm{~g}$ of CCS can be produced. Furthermore, $7 \mathrm{ml}$ of butanol per $100 \mathrm{~g}$ of CCS can be produced assuming the yield of $0.27 \mathrm{~g}$ butanol $/ \mathrm{g}$ glucose reported by Al-Shorgani et al. [50], and Jaramillo et al., [51]. Moreover, the scheme a can be used for xylitol production with a rate of $8.93 \mathrm{~g}$ per $100 \mathrm{~g}$ of CCS considering the yield of $0.73 \mathrm{~g} / \mathrm{g}$ reported by Roberto et al. [52], using Candida guilliermondii as microorganism. Nevertheless, concentration, 
(a)
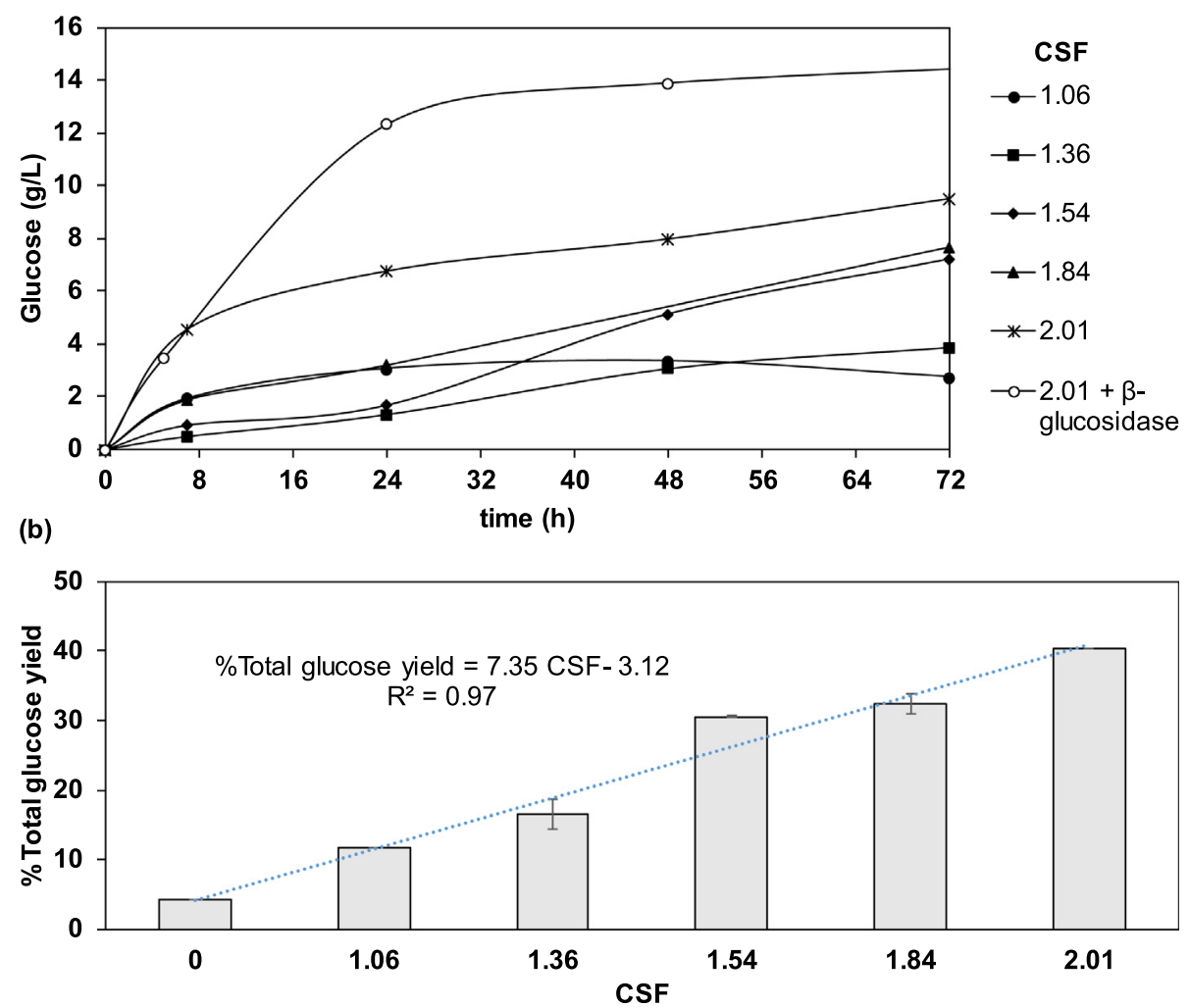

Fig. 2. a. Profile of glucose concentration of enzymatic hydrolysis of the CCS treated with dilute acid pretreatment. b. Correlation between CSF and total glucose yield.

detoxification and purification of both hydrolysates (i.e., rich in pentoses or hexoses) should be done. These additional steps can increase the overall cost of the process.

The mass balances presented can be used to determine the performance of the process in terms of mass and energy indicators. Several authors have reported these indicators. In this way, RuizMercado et al. [53], summarizes more than 26 mass efficiency indicators and 15 energy indicators. Nevertheless, only the process mass intensity (PMI) index was calculated. This index involves all the input streams and the desired product. Thus, the PMI index is calculated as the ratio between all the input streams and the mass flow of the desired product (i.e., liquid stream from the saccharification process) [54]. The PMI of both schemes is 1.92 and 2.03, respectively. These values are in agreement with the reported PMI values for the chemical industry, which varies from 5 to 50 [55]. However, other processing stages are missing (e.g., fermentation), which can increase the value of the indicator. On the other hand, the input and output energy balance of the process avoiding the utilities requirements can be done. The energy content of $1 \mathrm{~kg}$ of CCS is about $19.32 \mathrm{MJ}$, while the energy content of $1 \mathrm{~kg}$ of glucose is $15.55 \mathrm{MJ}$. In this way, the output to input energy ratio of the pretreatment process is $8.32 \%$ and $16.61 \%$ in the first and second

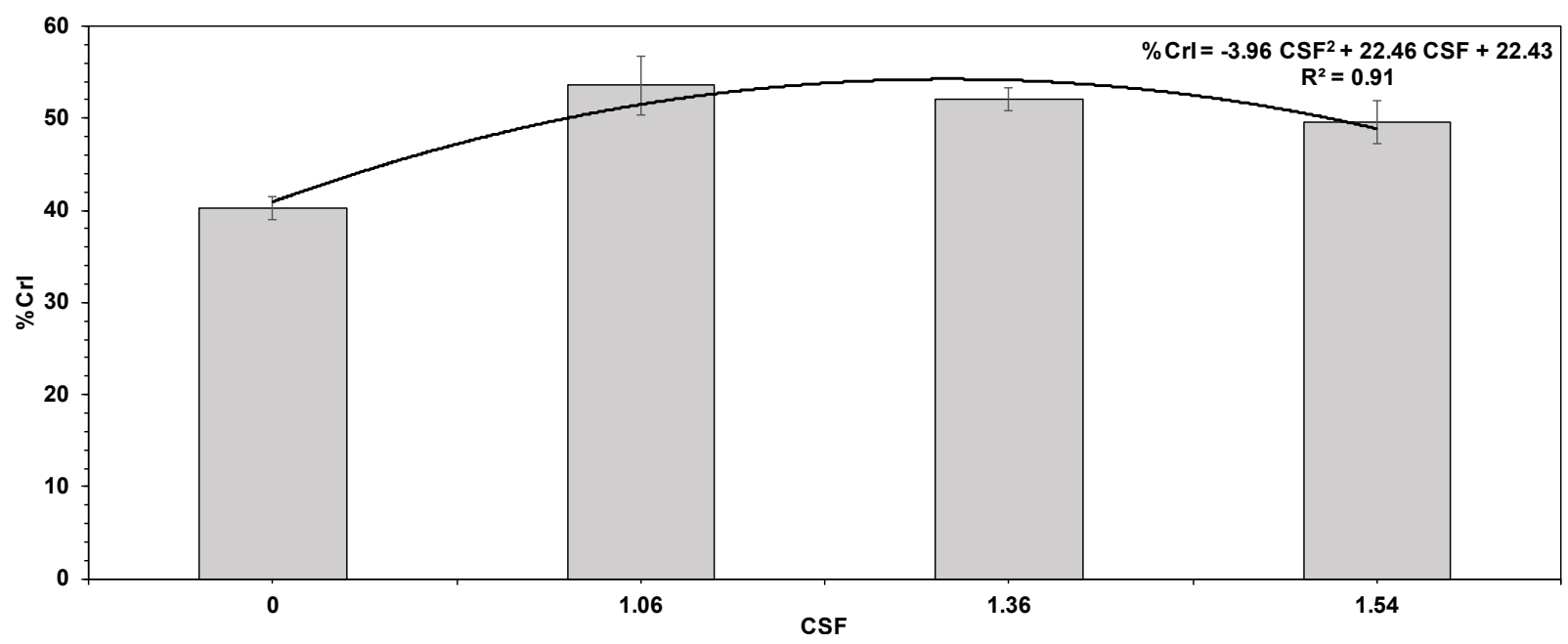

Fig. 3. CrI of CCS and treated solids derived of the dilute sulfuric acid pretreatment. 
(a)
100 g CCS d.b.

$\begin{array}{lr}\text { Glucan } & 42.62 \mathrm{~g} \\ \text { Xylan } & 21.18 \mathrm{~g} \\ \text { Arabinan } & 1.29 \mathrm{~g} \\ \text { Acetyl groups } & 4.59 \mathrm{~g} \\ \text { Lignin } & 29.81 \mathrm{~g}\end{array}$

(b)
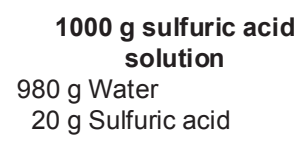

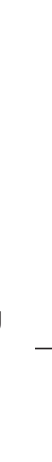
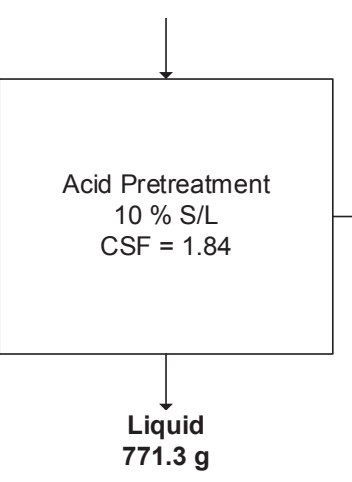

$\begin{array}{lr}\text { Glucose } & 0.94 \mathrm{~g} \\ \text { Xylose } & 12.24 \mathrm{~g} \\ \text { Arabinose } & 0.82 \mathrm{~g} \\ \text { Acetic acid } & 3.69 \mathrm{~g} \\ \text { Furfural } & 0.44 \mathrm{~g}\end{array}$

1.4 L Buffer

$11.38 \mathrm{ml}$ enzyme

Solid

70 g CCS pretreated d.b.

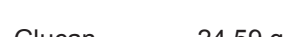

$\begin{array}{lr}\text { Glucan } & 24.59 \mathrm{~g} \\ \text { Xylan } & 3.15 \mathrm{~g}\end{array}$

Lignin $\quad 26.51 \mathrm{~g}$

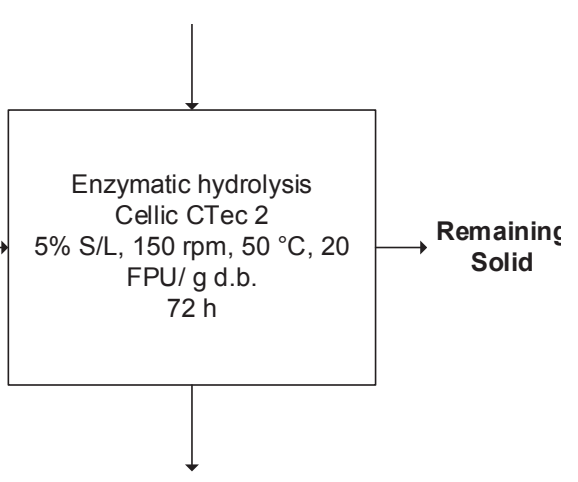

Liquid

Glucose $\quad 10.75 \mathrm{~g}$
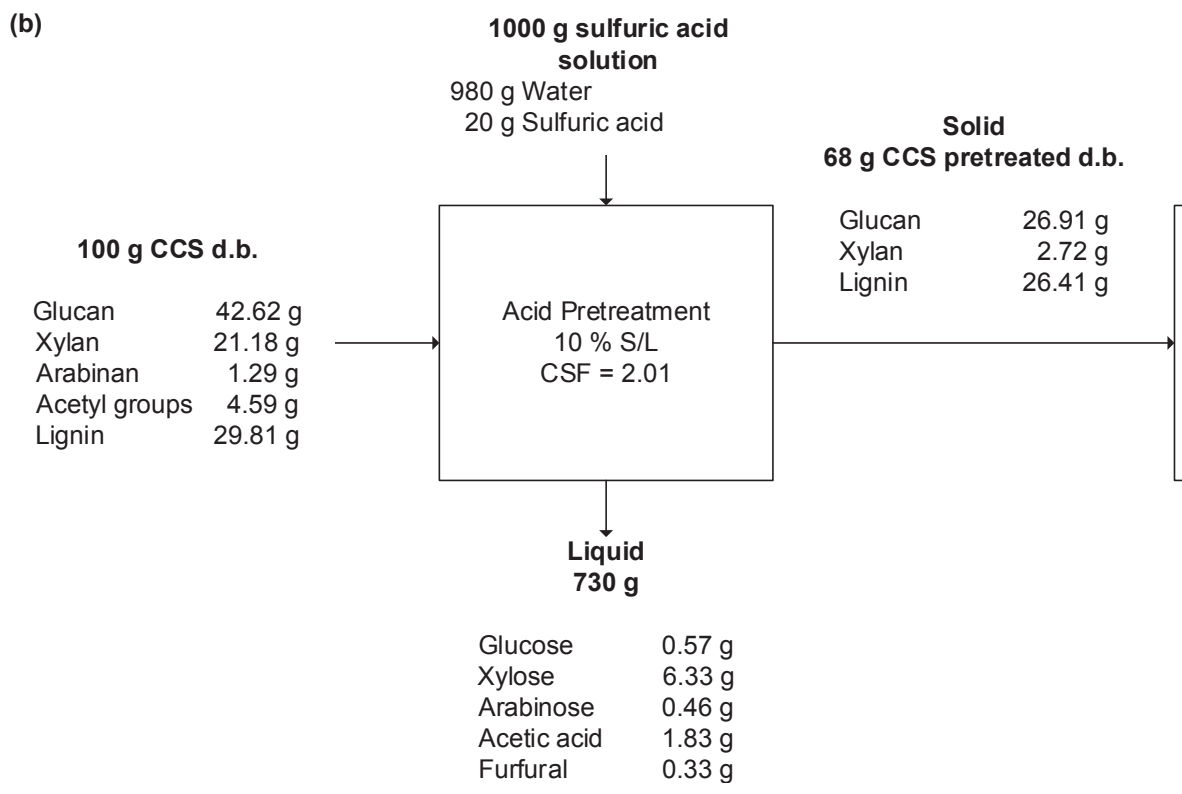

1.36 L Buffer

$11.05 \mathrm{ml}$ enzyme

$4.05 \mathrm{ml} \beta$-glucosidase

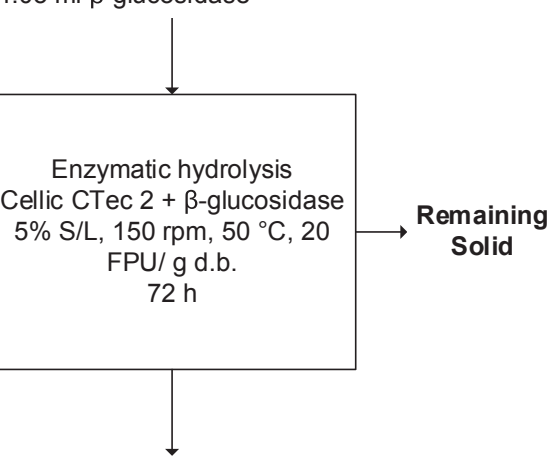

Liquid

Glucose $\quad 20.63 \mathrm{~g}$

Acetic acid

Furfural $\quad 0.33 \mathrm{~g}$

Fig. 4. Mass balance flow scheme of the overall process for the sugar release from CCS after dilute acid pretreatment. a. CSF of 1.08 and b. CSF of 2.01 .

schemes, respectively. These values suggest high-energy losses in both acid pretreatment and saccharification process due to the chemical conversion of the lignocellulosic matrix of the raw material. Therefore, the pretreatment stage of lignocellulosic biomass could be considered as one of the most inefficient processes in a biomass upgrading when using biotechnological conversion routes as main processing lines. This statement is in agreement with the simulation results reported by Piarpuzán et al. [56], where the chemical pretreatment process and saccharification stages consume more than $20 \%$ of the total energy input to the bioethanol production process.

The mass balances of the process can be used as input data to perform a simulation of the dilute acid pretreatment and saccharification process of CCS. From this, an economic analysis can be done. Nevertheless, a simulation of the process should be carried out to size the equipment in the process as well as find the total equipment cost. The conditions discussed to enhance the glucose yield of CCS allows suggesting low costs associated to maintenance and depreciation due to the use of low temperatures and acid concentrations. Finally, the use of sulfuric acid as catalyst to disrupt the lignocellulosic matrix of CCS can decrease the sustainability of the process. In fact, the use of sulfuric acid reduces the environmental sustainability of the process due to the possible releases of toxic compounds, which can affect environmental impact categories such as aquatic toxicity potential, terrestrial toxicity potential, an acidification potential. On the other hand, the social impact of the process is affected due to the use of hazardous materials, which can affect the health of the workers [58]. For these reasons, the overall sustainability of the acid pretreatment process should be improved using heterogeneous catalysts such as acid zeolites, which can reduce the environmental and social impact of the process as well as decrease the operational expenditures of the 
entire pretreatment stage [26].

\section{Conclusions}

The acid pretreatment and saccharification process were carried out to produce fermentable sugars using coffee-cut stems as raw materials. In the acid pretreatment process, two optimal pretreatment conditions were obtained depending on the purpose of the sugars production process. The first optimal conditions involve to pretreat the coffee-cut stems at $120^{\circ} \mathrm{C}, 180 \mathrm{~min}$, and acid concentration of $2 \% \mathrm{w} / \mathrm{w}$ (i.e., CSF 2.01 ) in the dilute acid process. Then, add $\beta$-glucosidase in the saccharification process to obtain a high glucose yield. Moreover, the addition of $\beta$-glucosidase reduces the residence time of the saccharification process allowing to reach a maximum cellulose conversion in $24 \mathrm{~h}$. The second optimal conditions involve to pretreat the coffee-cut stems at $120^{\circ} \mathrm{C}, 120 \mathrm{~min}$, and acid concentration of $2 \% \mathrm{w} / \mathrm{w}$ (i.e., CSF 1.84 ) in the dilute acid process. These conditions allow obtaining maximum total sugars recovery in the pre-hydrolysate liquor. Therefore, another biotechnological processes related to the xylose conversion can be included in the overall valorization of this residue. Finally, the mass balances of the process as well as the optimal conditions of the acid pretreatment process are the basis to simulate the real potential of coffee cut-stems as alternative feedstock to produce sugar-based products such as bioethanol, biobutanol, biogas, lactic acid, and xylitol avoiding the use of unselective kinetic models.

\section{Declaration of competing interest}

None.

\section{Acknowledgements}

The authors express their gratitude for the financial support to the Programme of ERASMUS + - International Credit Mobility celebrated between the Universidad Nacional de Colombia at Manizales and the University of Minho. The COLCIENCIAS program "Jóvenes Investigadores e Innovadores, Convocatoria 761 de 2016", the international collaboration project COLCIENCIAS - CONICYT with code PCCI140052, HERMES code 23567 (23876) entitled “Análisis Tecno-económico y Ambiental de Biorefinerías a partir de Residuos Lignocelulósicos con Esquemas de Recirculación de Microorganismos", the research program entitled "Reconstrucción del tejido social en zonas posconflicto en Colombia" SIGP code: 57579 with the project entitled "Competencias empresariales y de innovación para el desarrollo económico y la inclusión productiva de las regiones afectadas por el conflicto colombiano" SIGP code 58907. Contract number: FP44842-213-2018.

\section{References}

[1] Meerbeek K Van, Muys B, Hermy M. Lignocellulosic biomass for bioenergy beyond intensive cropland and forests. Renew Sustain Energy Rev 2019;102: 139-49. https://doi.org/10.1016/j.rser.2018.12.009.

[2] Cardona Alzate CA, Solarte Toro JC, Peña ÁG. Fermentation, thermochemical and catalytic processes in the transformation of biomass through efficient biorefineries. Catal Today 2018;302:61-72. https://doi.org/10.1016/ j.cattod.2017.09.034.

[3] Lennartsson PR, Erlandsson P, Taherzadeh MJ. Integration of the first and second generation bioethanol processes and the importance of by-products.

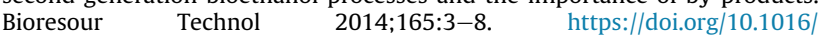
j.biortech.2014.01.127.

[4] Aristizábal MV Á Gómez P, Cardona ACA. Biorefineries based on coffee cutstems and sugarcane bagasse: furan-based compounds and alkanes as interesting products. Bioresour Technol 2015;196:480-9. https://doi.org/10.1016/ j.biortech.2015.07.057.

[5] Triana CF, Quintero JA, Agudelo RA, Cardona CA, Higuita JC. Analysis of coffee cut-stems (CCS) as raw material for fuel ethanol production. Energy 2011;36: 4182-90. https://doi.org/10.1016/j.energy.2011.04.025.
[6] MinAgricultura. Área, producción y rendimiento nacional por cultivo: café AGRONET; 2017. http://www.agronet.gov.co/estadistica/Paginas/default.aspx. [Accessed 10 January 2017].

[7] Quintero JA, Moncada J, Cardona CA. Techno-economic analysis of bioethano production from lignocellulosic residues in Colombia: a process simulation approach. Bioresour Technol 2013;139:300-7. https://doi.org/10.1016| j.biortech.2013.04.048

[8] Esteghlalian A, Hashimoto AG, Fenske JJ, Penner MH. Modeling and optimization of the dilute-sulfuric-acid pretreatment of corn stover, poplar and switchgrass. Bioresour Technol 1997;59:129-36. https://doi.org/10.1016/ S0960-8524(97)81606-9.

[9] Parajó JC, Vázquez D, Alonso JL, Santos V, Dominguez H. Prehydrolysis ofEucalyptus wood with dilute sulphuric acid: operation at atmospheric pressure. Holz Als Roh- Und Werkst 1993;51:357-63. https://doi.org/10.1007/ BF02663809.

[10] García CA, Peña Á, Betancourt R, Cardona CA. Energetic and environmental assessment of thermochemical and biochemical ways for producing energy from agricultural solid residues: coffee Cut-Stems case. J Environ Manag 2017 https://doi.org/10.1016/j.jenvman.2017.04.029.

[11] Sluiter A, Hames B, Ruiz R, Scarlata C, Sluiter J, Templeton D, et al. Determination of structural carbohydrates and lignin in biomass determination of structural carbohydrates and lignin in biomass 2012. 2011.

[12] Messaoudi Y, Smichi N, Allaf T, Allaf K, Gargouri M. Effect of instant controlled pressure drop pretreatment of lignocellulosic wastes on enzymatic saccharification and ethanol production. Ind Crops Prod 2015;77:910-9. https:// doi.org/10.1016/j.indcrop.2015.09.074.

[13] Yang B, Tucker M. Laboratory pretreatment systems to understand biomass deconstruction. Aqueous pretreat. Plant biomass biol. Chem. Convers. To fuels chem.. Chichester, UK: John Wiley \& Sons, Ltd; 2013. p. 489-521. https:// doi.org/10.1002/9780470975831.ch23.

[14] Li C, Sun L, Simmons BA, Singh S. Comparing the recalcitrance of Eucalyptus, pine, and switchgrass using ionic liquid and dilute acid pretreatments. Bioenergy Res 2013;6:14-23. https://doi.org/10.1007/s12155-012-9220-4.

[15] Cara C, Ruiz E, Oliva JM, Sáez F, Castro E. Conversion of olive tree biomass into fermentable sugars by dilute acid pretreatment and enzymatic saccharification. Bioresour Technol 2008;99:1869-76. https://doi.org/10.1016/ j.biortech.2007.03.037.

[16] Behera S, Arora R, Nandhagopal N, Kumar S. Importance of chemical pretreatment for bioconversion of lignocellulosic biomass. Renew Sustain Energy Rev 2014;36:91-106. https://doi.org/10.1016/j.rser.2014.04.047.

[17] Aristizábal Marulanda V. Jet biofuel production from agroindustrial wastes through furfural platform. Master Thesis. Universidad Nacional de Colombia. Departamento de Ingeniería Química; 2015.

18] Zhang J, Wang X, Chu D, He Y, Bao J. Dry pretreatment of lignocellulose with extremely low steam and water usage for bioethanol production. Bioresour Technol 2011;102:4480-8. https://doi.org/10.1016/j.biortech.2011.01.005.

[19] Adney B, Nrel JB. Measurement of cellulase activities laboratory. 2008. https:// doi.org/10.1016/j.biortech.2006.01.007.

[20] Miller GL. Use of dinitrosalicylic acid reagent for determination of reducing sugar. Anal Chem 1959;31:426-8.

[21] Selig M, Weiss N, Ji Y. Enzymatic saccharification of lignocellulosic biomass. Natl Renew Energy Lab 2008;1-5.

[22] Demírbas A. Bioethanol from cellulosic materials: a renewable motor fuel from biomass. Energy Sources 2005;27:327-37. https://doi.org/10.1080 00908310390266643.

[23] Sluiter A, Ruiz R, Scarlata C, Sluiter A J, Templeton D. Determination of extractives in biomass: laboratory analytical procedure (LAP). Golden, Colorado: Cole Boulevard; 2008. NREL/TP-510-42619, NREL/TP-510-426201.

[24] Tolosa RA, Jimenez-Obando G, Arias NP, Cardona CA, Giraldo O. Cementicious materials reinforcement using Angustifolia kunth bamboo fiber covered with nanostructured manganese oxide. Ind Eng Chem Res 2014;53:8452-63. https://doi.org/10.1021/ie403958y.

[25] Segal L, Creely JJ, Martin AE, Conrad CM. An empirical method for estimating the degree of crystallinity of native cellulose using the X-ray diffractometer. Text Res J 1959;29:786-94. https://doi.org/10.1177/004051755902901003.

[26] Solarte-toro JC, Romero-garcía JM, Martínez-patiño JC. Acid pretreatment of lignocellulosic biomass for energy vectors production : a review focused on operational conditions and techno-economic assessment for bioethanol production. Renew Sustain Energy Rev 2019. https://doi.org/10.1016 j.rser.2019.02.024. 0-1.

[27] Gírio FM, Fonseca C, Carvalheiro F, Duarte LC, Marques S, Bogel-Łukasik R Hemicelluloses for fuel ethanol: a review. Bioresour Technol 2010;101: 4775-800. https://doi.org/10.1016/j.biortech.2010.01.088.

[28] Martínez-Patiño JC, Romero I, Ruiz E, Cara C, Romero-García JM, Castro E. Design and optimization of sulfuric acid pretreatment of extracted olive tree biomass using response surface methodology. BioResources 2017;12. https:/ doi.org/10.15376/biores.12.1.1779-1797.

[29] Jensen J, Morinelly J, Aglan A, Mix A, Shonnard D. Kinetic characterization of biomass dilute sulfuric acid hydrolysis: mixtures of hardwoods, softwood and switchgrass. Environ Energy Eng 2008;54:1637-45. https://doi.org/10.1002/ aic.

[30] Temiz E, Akpinar O. The effect of severity factor on the release of xylose and phenolics from rice husk and rice straw. Waste Biomass Valorization 2016. https://doi.org/10.1007/s12649-016-9608-z.

[31] Canettieri EV, Rocha GJ de M, de Carvalho JA, de Almeida e Silva JB. 
Optimization of acid hydrolysis from the hemicellulosic fraction of Eucalyptus grandis residue using response surface methodology. Bioresour Technol 2007;98:422-8. https://doi.org/10.1016/j.biortech.2005.12.012.

[32] Gonzales RR, Sivagurunathan P, Kim S-H. Effect of severity on dilute acid pretreatment of lignocellulosic biomass and the following hydrogen fermentation. Int J Hydrogen Energy 2016;41:21678-84. https://doi.org 10.1016/j.ijhydene.2016.06.198.

[33] Jacobsen SE, Wyman CE. Cellulose and hemicellulose hydrolysis models for application to current and novel pretreatment processes. Appl Biochem Biotechnol Part A Enzyme Eng Biotechnol 2000;84-86:81-96. https://doi.org/ 10.1385/ABAB:84-86:1-9:81.

[34] Gonzales RR, Sivagurunathan P, Kim SH. Effect of severity on dilute acid pretreatment of lignocellulosic biomass and the following hydrogen fermentation. Int J Hydrogen Energy 2016;41:21678-84. https://doi.org/ 10.1016/j.ijhydene.2016.06.198.

[35] Delgenes JP, Moletta R, Navarro JM. Effects of lignocellulose degradation products on ethanol fermentations of glucose and xylose by Saccharomyces cerevisiae, Zymomonas mobilis, Pichia stipitis, and Candida shehatae. Enzym Microb Technol 1996;19:220-5. https://doi.org/10.1016/0141-0229(95) 00237-5.

[36] Du B, Sharma LN, Becker C, Chen SF, Mowery RA, van Walsum GP, et al. Effect of varying feedstock-pretreatment chemistry combinations on the formation and accumulation of potentially inhibitory degradation products in biomass hydrolysates. Biotechnol Bioeng 2010;107:430-40. https://doi.org/10.1002/ bit.22829.

[37] Wang X, Tsang YF, Li Y, Ma X, Cui S, Zhang TA, et al. Inhibitory effects of phenolic compounds of rice straw formed by saccharification during ethanol fermentation by Pichia stipitis. Bioresour Technol 2017;244:1059-67. https:// doi.org/10.1016/j.biortech.2017.08.096.

[38] Morales-delaRosa S, Campos-Martin JM, Fierro JLG. Optimization of the process of chemical hydrolysis of cellulose to glucose. Cellulose 2014;21: 2397-407. https://doi.org/10.1007/s10570-014-0280-9.

[39] Hsu T-C, Guo G-L, Chen W-H, Hwang W-S. Effect of dilute acid pretreatment of rice straw on structural properties and enzymatic hydrolysis. Bioresour Technol 2010;101:4907-13. https://doi.org/10.1016/j.biortech.2009.10.009.

[40] Yu Z, Du Y, Shang X, Zheng Y, Zhou J. Enhancing fermentable sugar yield from cassava residue using a two-step dilute ultra-low acid pretreatment process. Ind Crops Prod 2018;124:555-62. https://doi.org/10.1016 j.indcrop.2018.08.029.

[41] Chiranjeevi T, Mattam AJ, Vishwakarma KK, Uma A, Peddy VCR, Gandham S et al. Assisted single-step acid pretreatment process for enhanced delignification of rice straw for bioethanol production. ACS Sustainable Chem Eng 2018;6:8762-74. https://doi.org/10.1021/acssuschemeng.8b01113.

[42] López-Linares JC, Romero I, Moya M, Cara C, Ruiz E, Castro E. Pretreatment of olive tree biomass with $\mathrm{FeCl} 3$ prior enzymatic hydrolysis. Bioresour Technol 2013;128:180-7. https://doi.org/10.1016/j.biortech.2012.10.076.

[43] Gütsch JS, Nousiainen T, Sixta H. Comparative evaluation of autohydrolysis and acid-catalyzed hydrolysis of Eucalyptus globulus wood. Bioresour Technol 2012;109:77-85. https://doi.org/10.1016/j.biortech.2012.01.018.

[44] Hsu TC, Guo GL, Chen WH, Hwang WS. Effect of dilute acid pretreatment of rice straw on structural properties and enzymatic hydrolysis. Bioresour Technol 2010;101:4907-13. https://doi.org/10.1016/j.biortech.2009.10.009.

[45] Kumar R, Mago G, Balan V, Wyman CE. Physical and chemical characterizations of corn stover and poplar solids resulting from leading pretreatment technologies. Bioresour Technol 2009;100:3948-62. https://doi.org/10.1016/ j.biortech.2009.01.075.

[46] García-Velásquez CA, Cardona CA. Comparison of the biochemical and thermochemical routes for bioenergy production: a techno-economic (TEA), energetic and environmental assessment. Energy 2019:232-42. https://doi.org/ 10.1016/j.energy.2019.01.073.

[47] Martínez-Patiño JC, Romero-García JM, Ruiz E, Oliva JM, Álvarez C, Romero I, et al. High solids loading pretreatment of olive tree pruning with dilute phosphoric acid for bioethanol production by Escherichia coli. Energy Fuel 2015;29:1735-42. https://doi.org/10.1021/ef502541r.

[48] Yu Q Zhuang X, Yuan Z, Wang Q, Qi W, Wang W, et al. Two-step liquid hot water pretreatment of Eucalyptus grandis to enhance sugar recovery and enzymatic digestibility of cellulose. Bioresour Technol 2010;101:4895-9. https://doi.org/10.1016/j.biortech.2009.11.051.

[49] Carrasco JE, Sáiz MC, Navarro A, Soriano P, Sáez F, Martinez JM. Effects of dilute acid and steam explosion pretreatments on the cellulose structure and kinetics of cellulosic fraction hydrolysis by dilute acids in lignocellulosic materials. Appl Biochem Biotechnol 1994;45-46:23-34. https://doi.org/ 10.1007/BF02941785.

[50] Al-Shorgani NKN, Shukor H, Abdeshahian P, Kalil MS, Yusoff WMW, Hamid AA. Enhanced butanol production by optimization of medium parameters using Clostridium acetobutylicum YM1. Saudi J Biol Sci 2016. https:// doi.org/10.1016/J.SJBS.2016.02.017.

[51] Jaramillo Obando JJ, Cardona Alzate CA. Analysis of the production of biobutanol in the acetobutilyc fermentation with clostridium saccharoperbutylacetonicum N1-4 ATCC13564. Rev Fac Ing Univ Antioquia $\mathrm{N}^{\circ}$ 2011:58:36-45.

[52] Roberto IC, de Mancilha IM, Sato S. Influence of kLa on bioconversion of rice straw hemicellulose hydrolysate to xylitol. Bioprocess Eng 1999;21:505-8. https://doi.org/10.1007/PL00009089.

[53] Ruiz-Mercado GJ, Smith RL, Gonzalez MA. Sustainability indicators for chemical processes: II. Data needs. Ind Eng Chem Res 2012;51:2329-53. https://doi.org/10.1021/ie200755k.

[54] Budzinski K, Blewis M, Dahlin P, D’Aquila D, Esparza J, Gavin J, et al. Introduction of a process mass intensity metric for biologics. Nat Biotechnol 2019;49:37-42. https://doi.org/10.1016/j.nbt.2018.07.005.

[55] Tobiszewski M, Marć M, Gałuszka A, Namieśnik J. Green chemistry metrics with special reference to green analytical chemistry. Molecules 2015;20: 10928-46. https://doi.org/10.3390/molecules200610928.

[56] Piarpuzán D, Quintero JA, Cardona CA. Empty fruit bunches from oil palm as a potential raw material for fuel ethanol production. Biomass Bioenergy 2011;35:1130-7. https://doi.org/10.1016/j.biombioe.2010.11.038.

[58] Young D, et al. Designing sustainable processes with simulation: The waste reduction (WAR) algorithm. Computers and Chemical Engineering 1999;23(10):1477-91. https://doi.org/10.1016/S0098-1354(99)00306-3. In press. 